\title{
A pedagogy of interconnectedness for encountering climate change as a wicked sustainability problem
}

\section{Lehtonen, Anna}

2018-10-20

Lehtonen , A , Salonen , A , Cantell , H \& Riuttanen , L 2018 , ' A pedagogy of interconnectedness for encountering climate change as a wicked sustainability problem ' , Journal of Cleaner Production , vol. 199 , pp. 860-867 . https://doi.org/10.1016/j.jclepro.2018.07.186

http://hdl.handle.net/10138/318035

https://doi.org/10.1016/j.jclepro.2018.07.186

cc_by_nc_nd

acceptedVersion

Downloaded from Helda, University of Helsinki institutional repository.

This is an electronic reprint of the original article.

This reprint may differ from the original in pagination and typographic detail.

Please cite the original version. 
Title Page

\title{
A pedagogy of interconnectedness for encountering climate change as a wicked sustainability problem
}

\author{
Corresponding Author \\ Anna Lehtonen, M.E. \\ University of Helsinki, Finland. \\ Department of Teacher Education. \\ Other Authors \\ Arto Salonen, PhD Adjunct Professor, \\ Helsinki Metropolia University of Applied Sciences, Finland. \\ Hannele Cantell, PhD Adjunct Professor, \\ University of Helsinki, Finland. \\ Department of Teacher Education. \\ Laura Riuttanen, $\mathrm{PhD}$, \\ University of Helsinki, Finland. \\ Department of Physics. \\ Wordcount 7151 (Text) +355 (Table 1.)
}




\section{Introduction}

The wicked sustainability problems of today can be understood as the results of ignorance of the consequences of consumption, inattention to human dependence on ecological realities and the exceeding of planetary boundaries (Steffen et al., 2015). Climate change is one of these wicked problems, as it is a huge, complex and systemic challenge, difficult to clearly define or foresee the consequences of solutions (Incropera, 2015). In addition, different stakeholders provide conflicting information related to climate change, its relevance and impacts due to different interests of knowledge. As a global issue, the implications and solutions need to be reflected both locally and globally. Furthermore, the challenges of maladaptive behaviour and the cultural and emotional aspects of climate change make it difficult to find efficient solutions to the problem or predict the results (Incropera, 2015).

Even with the complexity of today's alarming sustainability challenges, the tendency is to use simplifying and contrasting, seemingly quick and efficient problem-solving strategies. This tendency creates, strengthens and focuses on dualisms instead of on understanding the complex processes of change. An over-reliance on binary opposites has created a tendency to exaggerate differences, confound descriptions and encourage prescription. Differences become exaggerated, and descriptions and prescriptions are confirmed. The overburdened dualism overlooks continuities, underplays contingencies and overstates the internal coherence of social forms (Wacquant, 1996; Sayer, 1989, 666).

The major sustainability problems cannot be solved on the basis of our current way of living and will require a shift from traditional ways of thinking and acting upon environmental and socioeconomic problems (UNESCO, 2002, 2014; Tilbury, 2007). Climate change, as a wicked problem and a signal of severe sustainability challenges, requires carefully considered responses which consider the root causes, are based on a systemic understanding and are participatory, transformative and transgressive (Kagawa \& Selby, 2011; Sterling, 2009; Corcoran, Weakland \& Walz, 2017).

Transformative learning and education, challenging societal paradigms and the re-thinking of education to be more responsive are regarded as imperatives in sustainability education (Palmer and Neal, 1994; Pittman, 2004; Sterling, 2003; 2009; 2010; Wolff, 2011; Laininen, 2018). Ecological intelligence, a holistic awareness of interconnectedness and systems thinking have been regarded as essential in sustainability education and as the core competencies needed for solving the wicked problems related to sustainability (i.e. Palmer and Neal, 1994; Pittman, 2004; Sterling, 2004; 2009; Wolff, 2011; Glasser and Hirsh, 2016).

Despite decades of efforts to develop effective environmental education and education for sustainable development, severe gaps remain between education and sustainability (Wolff, 2011). The inconsistency between the reality of educational practices and the rhetoric of environmental education has been a real challenge (Sauve, 1999; Stevenson, 2007; Wolff, 2011). The serious dilemmas between sustainability and education can be understood as related to a fragmented worldview and the modern dualistic understanding of humanness (Wolff, 2011). Thus, in order to find effective approaches to sustainability education, it is relevant to understand 
how modernism still affects prevailing societal and cultural practices as well as education, even though there are signals of new and more sustainable ways of thinking emerging (Sterling, 2009; Wolff, 2011).

The purpose of this article is to provoke a critical reflection of the prevailing dichotomized thinking and the essentiality of awareness of interconnectedness, and their implications in sustainability education on the basis of the theoretical frame of modern dichotomies. In the article unsustainable thinking in dichotomies and a dualistic worldview are examined within the context of climate change.

The research questions are as follows: 1) What kind of dismantling of dichotomized thinking and awareness of interconnectedness is vital in designing sustainability education and why? 2) How were the principles of pedagogy of interconnectedness applied in practice of the design of Climate.now online course material for higher education?

In the sections that follow, first the origins of unsustainability and climate change, the modern dichotomized thinking related to alienation, unsustainability and climate change, and its reflection in education are explored, and the most problematic dichotomies related to sustainability education are illustrated in Figure 1. Second, the relevant aspects of the awareness of interconnectedness are demonstrated in Figure 2. are explained: relationalism, the eco-social approach, the socially constructed climate change and the socially organized emotional response to climate change, and the integration of different ways of knowing. Third, the critical aspects of the awareness of interconnectedness for sustainability education dealing with wicked problems are presented as the pedagogy of interconnectedness. Finally, in order to dismantle the gap between theory and practice, a case of university pedagogy, the design of the Climate.now course, is presented and analysed as an example of, how to apply the principles of a pedagogy of interconnectedness in practice of higher education.

\section{Material and method}

To construct the frame for a pedagogy of interconnectedness, the literature of environmental philosophy (Vogel, 2015; Orr, 1994; Naess \& Rothenberg, 1990; 2008) and sociology of climate change denialism (Norgaard, 2011), the philosophy of environmental education (Wolff, 2011) are brought together with sustainability literature. The prevailing thinking in dichotomies related to unsustainability and gaps in sustainability education are explored within the frame of modern dichotomies. The key dichotomies related to climate change, social-individual, nature-culture, mind-body, rational-emotional, and art-science are dismantled on a basis of theoretical reading for creating a basis for pedagogy of interconnectedness.

A case of interconnecting climate change education for higher education, Climate.now is presented and analysed by applying theory directed approach to content analyses (Hsieh \& Shannon, 2005). Climate.now (www.climatenow.fi) is online material designed for a 5 ECTS course on the basics of climate change. It was produced by a multidisciplinary group of experts 
in Finland in 2016 in transdisciplinary collaboration within natural, environmental, technical and educational scientists and artists from the University of Helsinki, the Lappeenranta University of Technology, and the Metropolia School of Applied Sciences in Finland, and funded by SITRA, Finnish Innovation Fund. The first, second and fourth authors of the article were involved in the designing process of the course material of Climate.now. The development process of the theoretical, pedagogical thinking of interconnectedness started separately but simultaneously with the designing of the Climate.now material, and continued after the course material was published.

The material of Climate.now contains written material, video lectures and interviews, assignments, tests and a guide for teachers including guide lines for contact sessions and criteria for assessment. The content of the material was analysed on the basis of pedagogy of interconnectedness, how the principles of pedagogy of interconnectedness were applied in the course material

\section{Dismantling thinking in dichotomies and the awareness of interconnectedness}

In the following sections, the modern dichotomies critical in designing sustainability education are dismantled and reflected on from several theoretical perspectives. The origins of unsustainability related to dichotomized thinking and the manifestation of this type of thinking in education are explored. In the end the vital awareness of interconnectedness for sustainability education is explained.

The modern era, characterized by the scientific and industrial revolution, is seen as the beginning of increasing consumption and unsustainability. The philosophical and scientific revolution of the Enlightenment defined natural resources as limitless and inexhaustible and thus legitimated the industrial revolution (Zafirovski, 2010; Gay, 1996). According to Richard Norgaard (1994), atomism, mechanism, universalism, objectivism and monism, the metaphysical premises deriving from the modernism dominant in Western culture, help explain the cultural and biological destruction (Norgaard, 1994; Laininen, 2018). Anthropogenic activities such as deforestation, agricultural practices and the burning of fossil fuels, which have resulted in large shifts among carbon pools related to global warming (IPCC, 1995), originate from the modern era and the philosophical revolution of the Enlightenment.

\subsection{Modern dichotomized thinking and education}

Dichotomized thinking, that is, dividing and separating ideas and objects into two opposing parts or classifications, is regarded as typical of the modern era. ${ }^{1}$ In the era of the Enlightenment, the

\footnotetext{
${ }^{1}$ Modernity as a historical category refers to a period characterized by a questioning or rejection of tradition; the prioritization of individualism, freedom and formal equality; faith in inevitable social, scientific and technological progress and human perfectibility; rationalization and professionalization; a movement from feudalism (or
} 
idealization of individual rational minds and reason as the primary source of authority was the grounding philosophical principle guiding the development of scientific methods and knowledge (Outram, 2006). Distancing the knowing subject from the object has promoted an instrumental relation with nature, the body, other people and society (Wolff, 2011, 84-85). Human alienation from nature is seen as related to a dualistic understanding of the mind/soul and the body. Reason is regarded as a human quality implying the superiority of humans over other animals in Western philosophy. Philosophical differentiation of the mind and the body as separate units, most famously associated with Cartesian dualism (Crane \& Patterson, 2012), has been a constant mindset throughout history. (Wolff, 2011, 85.) The mind and body dichotomy has been central in promoting an instrumental value relation to nature in contrast to nature having intrinsic values.

Dichotomized thinking is integrated into modern education, where the ideals of rational humanity and objective knowledge are inherent. A typical goal of modern education is a rational individual citizen with the skills to succeed in competition and a fragmented knowledge of different fields and disciplines (Orr, 1991). As a result, the focus in education has not been the understanding of human dependence on holistic socio-ecological systems; the limits of human life; questions of will and desire; and social responsibility, emotions, imagination and embodied knowing (Orr, 1991; Sterling, 2009; Kagawa \& Selby, 2011; Wolff, 2011). Instead, educators and learners have been provided with good skills of analysing, categorising and labelling things, seeing detail and dealing with parts and focusing on one factor or goal at a time. However, to deal with reality of wicked sustainability issues the skills of reframing, making synthesis, coping with uncertainty, resilience, and multiple intelligences and ways of knowing are necessary (Sterling, 2009).

According to Lili-Ann Wolff (2011), profound gaps exist between education and sustainability that can be understood as related to a segregated worldview and the modern dualistic understanding of humanness. These include the gulf between human and nature, knowledge and action, the rhetoric of environmental education and educational practice, the researcher and the object, knowledge and power, different generations, and the dilemma between individual desire and social obligations. To address the challenging gaps of sustainability education, Wolff (2011) defines the goals of sustainability education as the promotion of self-transformation through selfunderstanding and self-training, the development of social relations and collective responsibility, and the promotion of an understanding of the natural world and life on a global scale. In the following sections the essential goals of sustainability education are enlightened in relation to dichotomies of nature-culture, social-individual, mind-body and reason-emotion, and artscience.

\subsection{Alienation and dichotomized thinking}

agrarianism) toward capitalism and the market economy; industrialization, urbanization and secularization; and the development of the nation-state and its constituent institutions and forms of surveillance (Foucault, 1995, 170-77). 
According to Steven Vogel (2015), climate change as an unintended commons is a tragedy. It is an unintended result, produced in both individual and collective practices. Vogel $(2015,207)$ refers to Marx' concept of alienation ${ }^{2}$ when explaining how climate change is an unintended socially produced result. Human alienation from nature and socially produced reality has resulted in severe sustainability challenges such as climate change. According to Vogel (2015), this alienation might be the reason for the lack of understanding of how individuals interact with the common physical, ecological and social reality of climate change. Sterling (2003) describes the phenomenon of alienation is an epistemological battle heated by the tension between the parts and the whole. ${ }^{3}$ Separateness is an operative way of knowing, and this thinking reflects itself throughout Western culture. Relations are seen as win-lose games instead of win-win possibilities, and the focus is on parts of the system instead of their relations (Sterling 2003; 2009; 2010; Laininen, 2018). Alienation has been used as a concept to describe a sense of loss, harnessing subjectivity to objects for capitalist interests. This has proceeded to new dimensions in the sphere of digital technology and cyberculture. In the time of digitalization the exploitation involves the human mind, language and emotions in order to generate value. (Berardi, 2009.)

A modern dualistic worldview and alienation have replaced the perception of man as an integral part of nature. Seeing nature as an object of instrumental benefit has led to attitudes of indifference and overconsumption (Wolff, 2011). The impact of private individual acts or thoughts is not generally considered to have significance in the social and global reality. The effects of human behaviour on socio-ecological systems has not been considered in individual or institutional decision making within societies. Due to globalization, the distant ecological and social consequences and impacts of consumption on other people and ecology have become obscured (Conca, Maniates, Princen, 2002). Focusing on local action and solutions, while neglecting global impacts or the impacts on distanced localities has induced severe sustainability challenges. We are living in the Anthropocene era, in a reality where human activities impact the environment on all scales (Crutzen 2002, 2006; Cook et al., 2013), Human intervention has affected everything; thus, everything in the world is different from what it would otherwise "naturally" be. Through land use activities, producing pollution and waste, and altering geochemical cycles, and changing the climate, people have made every spot on Earth manmade and artificial. (Crutzen 2002; 2006; Vogel, 2015.)

\footnotetext{
${ }^{2}$ According to Marx's account, to be alienated from something is to fail to recognize it as something one has helped to produce; under alienation, the objects built by human practice both the particular commodities built by labour and the broader phenomena generated by the "invisible hand" - appear as independent powers over and against human lives. In Marx's sense, we cannot be alienated from "nature", but we can be (and are) alienated from the built environment - in that we do not recognize its sociality and its builtness (Vogel, 2015). ${ }^{3}$ Decontextual separation - a deep-seated belief that the wellbeing of the isolated part is won in the struggle against other parts - is in opposition to the understanding that the wellbeing of the part depends on the wellbeing of the whole and vice-versa (Sterling, 2003).
} 
People have ignored the human dependence not only on nature but on other people. Individuals have been separated from the social production of reality, the common ecological, social, material and nonmaterial reality. Social and economic systems are separated from nature, and decisions are based on reasoning with a false assumption of the separateness of emotions and values (Laininen, 2018). However, the maladaptive behaviour, the social and psychological aspects of climate change, has brought sustainability problems to a wicked level. Research has proven that scientific knowledge about ecology and human dependence on nature does not solely alter sustainable behaviour (Kollmuss \& Agyeman, 2002). The neglect of ethical and emotional dimensions of climate change makes climate change education meaningless and inefficient (Selby, 2010).

The modern dichotomies most problematic from the perspective of sustainability education and climate change are illustrated in Figure 1.

Figure 1. Modern thinking in dichotomies enhancing unsustainability

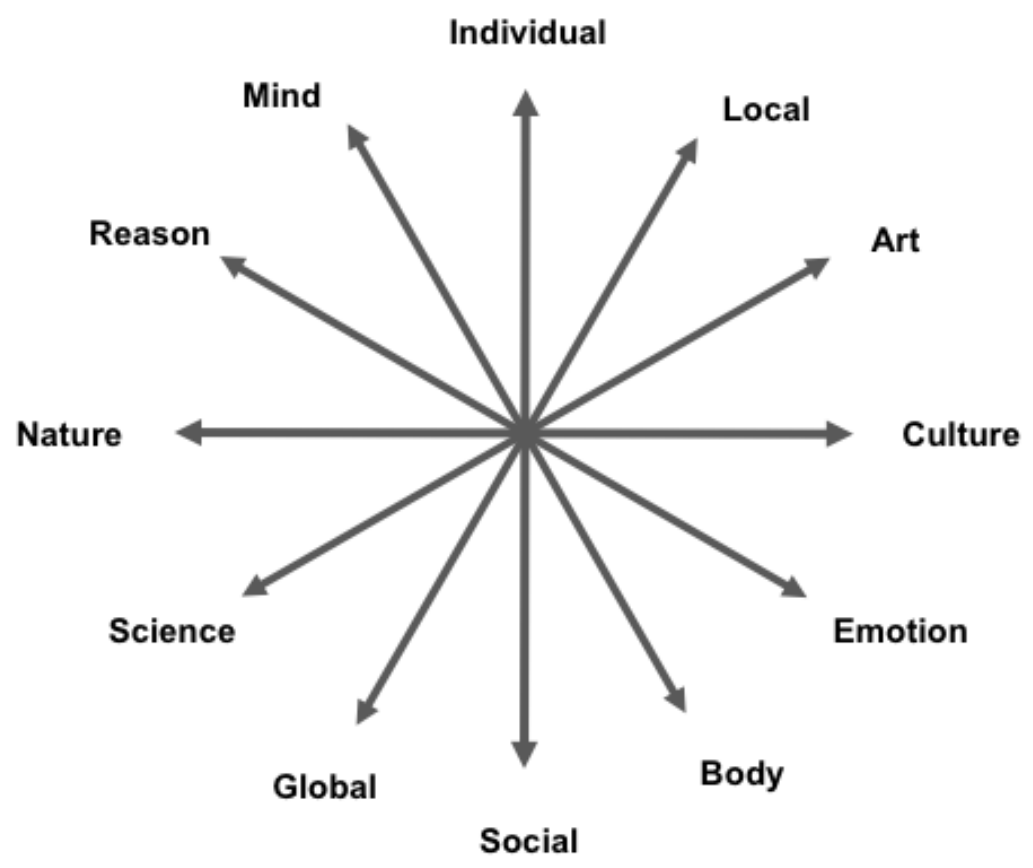

At the core of the sustainability challenges are the dichotomies between the individual and social, and culture and nature. People have become alienated from socio-ecological systems (Marcott et al., 2013). A dualistic worldview has replaced the perception of man being an integral part of nature (Bateson,1972). Alienation and denial are socially produced and organized cultural responses to climate change (Norgaard, 2013; Vogel, 2015). An understanding of the global impact of local decision making is both missing and essential in a globalized world with global sustainability threats. However, at the core of this dichotomized thinking is the mind and body dualism, related to the idealization of reason and the neglect of emotional attachment and ethical awareness. Dismantling the dichotomy of art and science is essential for enriching 
scientific knowledge with different ways of knowing in order to illuminate the human response to climate change.

\subsection{Sustainability as awareness of interconnectedness}

If unsustainability is seen as related to dualist, dichotomized thinking, finding effective approaches to sustainability challenges and decreasing global warming requires a holistic understanding of interconnectedness ${ }^{4}$ (Nash, 1989; Kagawa \& Selby, 2010) and relationalism (Naess \& Rothenberg, 1990). Interconnectedness emphasizes the relational nature ${ }^{5}$ of things. According to relationalism, things exist and function only as relational entities (Naess \& Rothenberg, 1990, 56).

From a sustainability perspective, interconnectedness can be found in several dimensions. People are part of eco-social systems, and cultural attitudes and responses to climate change are socially produced and organized. Natural conditions and people's living conditions are interdependent, and local and global are interrelated. Each person is involved in the continuous social construction of reality, and the individual choices of living and thinking have an impact on the common global reality of climate change. In addition, individuals have a crucial role in socialization processes, defining norms and taboos by acting or not acting, speaking or staying quiet, and even by thinking. Sustainable decision making is based on relational intelligence including both the emotional and ethical intelligence (Pless \& Maak, 2005) and common good thinking (Glasser, 2017). The above mentioned essential aspects of the interconnectedness of sustainability are explained in the following paragraphs from different theoretical perspectives and illustrated in Figure 2 at the end of this section.

\section{The eco-social approach}

The eco-social approach to education, defines the human-nature relationship as asymmetric because humans are fully dependent on nature, even though nature can flourish without humans (Salonen, 2014). In the big picture, an asymmetric interconnectedness also exists between the biosphere, society and the economy in the real world. Without a well-functioning biosphere, there can be no society, and without society, there can be no societal functions, including an economy (Salonen, 2014; Salonen \& Konkka, 2015). The economy is a sub-system of a larger finite system, the biosphere (Max-Neef, 2010, 203-204). Therefore, the economy is also a subsystem of society (Pilipenko, 2015). It is impossible to benefit from the prosperity created by economic growth if the environment where humans live is ruined. This means that the common good of all living creatures is also good for an individual human being on a longer time scale. Commons thinking refuse the logic well-being depending on exploiting the other people or the environment, but elevates understanding of interdependence and common good (Kenrick, 2009).

\footnotetext{
${ }^{4}$ For historical perspectives on interconnectedness in environmental philosophy, see Nash (1989).

${ }^{5}$ Relationalism refers to the theory of reality that interprets the existence, nature and meaning of things in terms of their relationality or relatedness. In the relationalist view, things are neither self-standing entities nor vague events but relational particulars (Naess \& Rothenberg, 1990).
} 


\section{Socially constructed climate change}

Steven Vogel $(2015 ; 36)$ underlines the essentiality of understanding the social reality of climate change as socially constructed and produced unintendedly in both individual and collective practice. He refers to the philosophy of social constructionism ${ }^{6}$ for unmasking the hidden and forgotten processes of the collective production of social reality. According to social constructionism, knowledge should be understood as an active process, as we come to know nature only through transforming it (Vogel, 2015, 45-47).

Wolff (2011) refers to Foucault's thinking and describes the essential understanding of knowledge similarly to Vogel. Knowledge is "not an objective or a matter of free-floating facts it is a collective undertaking that involves everyone individually and socially in interaction with the many relations of a person's life, both rationally and emotionally, including self-relation, relation to others, and to physical nature."

\section{The socially organized emotional response to climate change}

The emotional response to climate change is socially organized and adapted in social interaction, according to the sociology of climate change. According to Kari Mari Norgaard (2011), individuals often collectively distance themselves from information about ecological threats and behaviour related to them because of norms of emotion, conversation and attention. Furthermore, our social environment provides us with a general idea of what we can disengage from and what we should repress from our consciousness or ignore. Inattention occurs in response to social circumstances and is carried out through the process of social interaction. The prevailing responses to climate change, literal, interpretive and implicatory denial, which minimize the psychological, political and moral implications of climate change, are all socially organized (Cohen, 2001, Norgaard, 2011; 9).

Moreover, the emotional aspect of climate change needs to be carefully considered as ecoanxiety is a severe issue (Pihkala, 2017). People need the help of supportive communities to cope with climate change anxiousness and great fears about the future (Norgaard, 2011). The threat of climate change to the continuation of life, and the culpability of all people in its cause are psychologically unbearable issues (Lehtonen \& Välimäki, 2013). Besides, people need an emotional attachment ${ }^{7}$ to nature in order to demonstrate environmentally responsible behaviour (Orr 1994) and experience the connection embodied with other people and nature in order to have the motivation to take care of them (Martusewicz, Edmundson \& Lupinacci, 2014). Embodied and emotional awareness is essential, as emotional literacy and ethics are related

\footnotetext{
${ }^{6}$ The theory of social constructionism highlights the fact that the world has a social and historical origin and is actively, socially constructed. Social constructivism applies the ideas of social constructionism to psychology and education. According to social constructionism, concepts are created by human beings, and this creation occurs in a historical social context, but it does not follow that the referents of those concepts are thus created (Hacking, 1999, Vogel, 2015; 35), as the ecology of our planet is not socially constructed.

${ }^{7}$ Biofilia, having the meaning of affinity and love for all life (Orr 1994).
} 
(Nusbaum, 2003; Goleman, 2006). The emotional aspect of learning should have a focus in education as emotional awareness, since emotions affect learning and thinking (Phillips, 2009). In addition, emotional and embodied literacy are important for creating a common vision of sustainable well-being. According to Naess (2008: 23). "What is good life, goes primarily through emotions."

\section{Integration of different ways of knowing}

For deepening the understanding of critical sustainability issues, discovering connected identities and creating new ideas and alternative visions of sustainable life, new ways of thinking are needed as wicked problems can't be solved with the same strategies of knowing, that has resulted in problems. To deepen the understanding of different dimensions of climate change, transdisciplinary knowing is relevant. According to Kagawa and Selby (2010, 242-243), "There is a need for complementary and recursive use of artistic, embodied, experiental, symbolic, spiritual, and relational learning, especially in the vital educational task of reconnecting learners to the earth while enabling them to discover their connected identity and realize their full potentials." Integration of various ways of knowing helps in construction of a multidimensional understanding of phenomena.

Enriching rationality, analytic and mechanistic ways of knowing with creative ways of knowing, emotional and ethical intelligence are critical in envisioning and creating a more sustainable future (Kagawa \& Selby, 2011). In addition, experiental and embodied knowing, the integration of mind and body is crucial in sustainability to make knowledge about interconnectedness meaningful. The integration of art and science in art-based learning processes have an immense potential in learning for sustainability (Eernstman, and Wals, 2013) and in addressing the modern dilemmas of education. Personal meaning perspectives can become enriched in artistic dialogue and encounters with other people and the world. For example, concepts such as sustainable development or sustainable future can be re-embedded into the world and practice of living by applying art-based methods (Eernstman \& Wals, 2013).

To improve the situation of sustainability, the crucial dimensions of an awareness of interconnectedness are illustrated in Figure 2. The spiral in Figure 2 demonstrates the need for dismantling, deconstructing and integrating dichotomized thinking on the meta level and designing practices where they are integrated. The spiral begins from the middle, and the dismantling of dichotomies starts from the individual's reflection on experiences and ways of seeing the collective reality. The role of science, philosophy and education is to provoke the dismantling and deconstructing of dichotomies, to create pathways as theories, concepts and practices in between dichotomies, and to promote the understanding of interconnectedness, common goods thinking, interdependence and the nature of the eco-social human being. 
Figure 2. Awareness of interconnectedness for sustainability

\section{Individual}

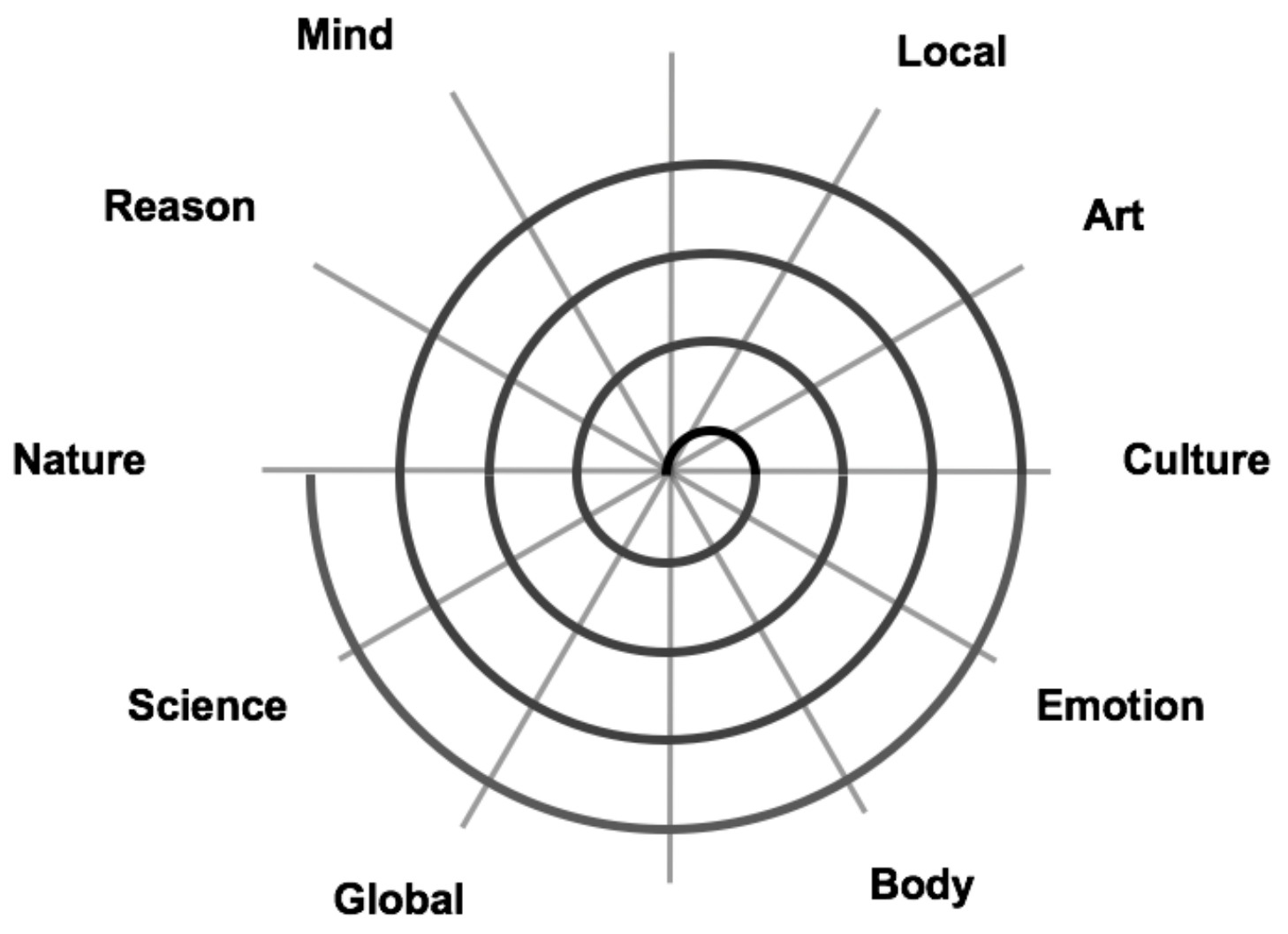

Social

To summarize, combating climate change necessitates dismantling the modern fragmented worldview and alienation: thinking in dichotomies needs to be demolished. The awareness of interconnectedness is central in the construction of sustainable societies and lifestyles and in education. Encountering climate change and other related big challenges of unsustainability necessitates critical consideration of effective, transformative pedagogies to provide people with systems thinking ${ }^{8}$ (Glasser \& Hirsh, 2016) and critical and creative learning skills (Kagawa \& Selby, 2010). In the following chapter, we present the principles of a pedagogy of interconnectedness defining the vital awareness of interconnectedness contra thinking in modern dichotomies is essential in education.

\footnotetext{
${ }^{8}$ Systems thinking means awareness of linkages and interactions between elements that compose the entire system of a persisting problem (Capra, 1996).
} 


\section{Principles of a pedagogy of interconnectedness}

As a conclusion of the theoretical exploration of the problematic thinking in dichotomies and needed integration in the section 3., the principles of pedagogy of interconnectedness define the critical awareness of interconnectedness for sustainability education. The pedagogy of interconnectedness aims at enhancing the understanding of the world and humans as relational: recognizing the interdependence of society and nature, the local and global, and seeing the common reality as socially constructed. In order to promote awareness of interconnectedness, the humanness and learning needs to be considered in a holistic way, and the perspectives of knowing need to be widened through the integration of science and arts in education.

\section{Essential awareness of interconnectedness in sustainability education}

A view of oneself, the human and the world as relational

Integration of human culture and nature, the local and global

- Understanding of the interdependence of and becoming connected with nature and society, global ecosystems and the community of people.

- Becoming aware of oneself being a part of and having an impact on global eco-social reality and global ecosystems.

Integration of the individual and social

- Becoming aware of how the individual and common good are parallel on a longer time scale.

- Becoming aware of how emotional and value-based responses to climate change are socially organized by norms and taboos and how every individual is part of this socialization process. Individual acts, thoughts and attitudes construct the common reality and matter.

Integration of mind-body, reason and emotion, intuition, and arts and science

- Becoming connected with oneself, with integrated and embodied experiences, thoughts, feelings, needs, values and your own creativity related to the body and mind.

- Becoming aware of how emotions interfere in knowing and guide personal values.

- Deepening the understanding of humanness and search for sustainable humanness and solutions for a sustainable life.

- Searching for alternative ways of seeing reality; a creative visioning of sustainability.

A pedagogy of interconnections enhances the need for special, integrative pedagogical approaches considered in line with learning goals for promoting the awareness of interconnectedness. Collaborative learning, phenomenon-based learning and arts-based learning as experiental, embodied, collaborative and creative learning approaches are suggested as effective means that could enhance an awareness of interconnectedness. Common goods thinking 
can be learned in the practice of collaborative and participatory learning that integrate individual and social awareness in pedagogical practices and facilitate empowerment in collaboration. Transdisciplinary studying real world issues, can enable the integration of knowledge about the human and nature, and the nature and society of different fields. Through integration of arts in education it is possible to critically reflect on personal and cultural images, attitudes, norms and taboos. Furthermore, the integration of arts and science enables exploring humanity and its relations, widening perspectives and looking at reality differently in alternative ways, which are imperatives for future thinking and essential elements of art-based learning (Boeckel, 2013).

\section{Climate.now: Interconnecting climate change education}

Climate.now, an online course material for a higher education institution, is an example of practice and analysed from the theoretical basis of the pedagogy of interconnectedness. Climate.now consists of multidisciplinary online material for a multidisciplinary study and a teaching module ( 5 credits) on the basics of climate change. The study material contains written material, video lectures and interviews, tests, various applied assignments such as a learning diary and project work, and a guide for teachers that will help anyone familiarize themselves with the basics of climate change. In the Table 1. (Attached in the end of the article) the goals and the content of Climate.now are related to the modern dichotomies and the different dimensions of pedagogy of interconnectedness.

Climate.now is an example of interconnecting climate change education on many aspects. The design of the course material is transdisciplinary, and the material was produced in multidisciplinary collaboration with natural, environmental, social and educational scientists and artists. The learning packages of Climate.now offer multidimensional perspectives on climate change as an interconnected physical, ecological, societal, cultural and ethical issue. The course material includes several interconnected learning packages, such as Climate change in different fields or Big issues, covering large topics such as food production and the role of forests in climate change. Students work in multidisciplinary groups during the course and complete multidisciplinary project assignments on prepared topics. The collaborative learning in study groups may offer experiential learning about common good thinking in practice.

In the teachers' guide, the learning approach is defined as systemic, participatory, dialogic and experiential learning in which climate change is discussed in different connections and contexts. In addition to understanding climate change and the related interactions, learning also focuses on becoming aware of different attitudes and ways of thinking.

An eco-social, global and ethical awareness of interconnectedness is deepened by the project assignments of Climate.now. These assignments consider Himalayan glaciers, Hurricane Katrina, which hit New Orleans in 2005, and stories of individual people in different parts of the world in very many aspects containing natural scientific, social scientific and ethical questions. 
The goal of the project assignments is for students to apply the topics in the course to the contexts given and, through local and global perspectives, gain a more in-depth understanding of what they have learned.

A personal relationship with the topic, integration of social and individual, and critical thinking are enhanced by writing learning diaries. In the learning-diary the students are asked to reflect on the meaning of the content to themselves as persons, as a member of a society and to their field of study. The learning diary has a crucial role for integrating the individual and common awareness, as the diary should be discussed in the peer-group meetings. Moreover, the aim of writing in a diary is to promote reflection on climate change from ethical and emotional aspects, and to connect the new learning experiences and content to what has been learned before.

Furthermore, the course design aims at engaging students by promoting awareness of each person and field of study having a crucial role in climate change, this is strengthened especially through creative project assignments searching for solutions toward a society where climate change has been resolved. Within Climate.now, integration of individual and social, promoting active agency is enhanced by reflective assignments on the different roles one has in relation to climate change and the role each field could have in combating climate change. At the end of the course the students are asked to use their imagination and creativity to look for solutions in a utopian assignment, imagining a world where climate change is resolved and designing a climate project of their own. Becoming aware of the meaningful role each person has in climate change might activate people to engage in critical reflection of prevailing responses, and the search for a new, more sustainable way of living.

The principles of a pedagogy of interconnectedness are visible in the criteria for assessment. The criteria include studying and examining the issues in depth from various points of view; having a transdiciplinary approach and demonstrating systemic thinking; displaying a transformative approach to climate change; critical, creative and ethical thinking; awareness of the local and global as interrelated; critical reflection; and meta-thinking in their personal studying.

\section{Concluding remarks}

In order to strengthen the transformation to cultural and societal sustainability through education, critical exploration of prevailing thinking and pedagogical practices is a prerequisite. To strengthen the effectiveness of educational responses, educational practices need to be designed in line with learning goals. This demands critical thinking on the meta level. In this article the roots of unsustainability are examined from the point of view of alienation and fragmented thinking related to modern dichotomies. As a result of the theoretical exploration of the modern dichotomies that strengthen alienation, the educational response called pedagogy of interconnectedness is outlined.

Pedagogy of interconnectedness aims at promoting human interconnectedness through enhancing awareness of interconnectedness in educational practices. This means seeing humans and learning in a holistic way: integrating minds and bodies, reason and emotion; and seeing the world and humans as interconnected: the interconnectedness of the individual and social, nature 
and culture, the local and global, and the integration of art and science to create new insights and alternative ways of understanding.

Identifying interconnectedness contra the prevailing dichotomized thinking and making interconnectedness visible in educational practices make it possible to dismantle the prevailing segregated and dichotomized thinking. Redesigning education for sustainability necessitates the consideration and development of new learning approaches. Collaborative, participatory learning and exploring real-life issues could integrate individual and social realities, foster active agency and relational systems thinking. Moreover, integrating art and science into learning processes can enable enriching rational thinking with intuitive thinking and cultivate creativity and an embodied and emotional understanding of the wicked sustainability challenges of humanness.

In this article, a case of university pedagogy, Climate.now, the online course for higher education, was presented as an example of how the principles of pedagogy of interconnectedness could be applied in practice. In the course design of Climate.now, transdisciplinary, transformative and collaborative learning are promoted by studying in multidisciplinary study groups; systemic understanding is provoked by integrative and creative learning assignments; critical self-reflection and ethical awareness are enhanced in the instructions of the learning diaries; and these goals were ensured by the criteria for assessment.

In the complex reality of climate change, redesigning education for sustainability and consideration of new learning approaches are needed on all levels of education. The core of pedagogy of interconnectedness is to enhance critical reflection of dualistic and segregated ways of thinking and to promote the awareness of interconnectedness. The focus is on making visible the contradictions of the prevailing thinking and recognize unexpected, bewildering connections. This enables a more realistic understanding of the complexity of climate change and the creation of novel, various engaging encounters with climate change. With their focus on interconnectedness, these various approaches together can create a powerful response to climate change as the wicked burning sustainability challenge of our time.

\section{Funding}

This work was supported by the Emil Aaltonen Foundation. Climate.now was funded by the Finnish Innovation Fund Sitra.

\section{References}

Bateson, G. (1972). Steps to an ecology of mind: Collected essays in anthropology, psychiatry, evolution, and epistemology. University of Chicago Press.

Berardi, F. (2009). The soul at work: From alienation to autonomy. Semiotext (e). 
Boeckel, J. V. (2014). At the heart of art and earth: An exploration of practices in arts-based environmental education Aalto University.

Capra, F. (1996). The web of life: a new scientific understanding of living systems (1st Anchor Books ed). New York: Anchor Books. p. 30

Cohen, S. (2001). States of Denial: Knowing about Atrocities and Suffering. Cambridge: MA: Polity Press.

Conca, K., Maniates, M., \& Princen, T. (Eds.). (2002). Confronting consumption. MIT press.

Cook, J. \& Nuccitelli, D. \& Green, S. \& Richardson, M.\& Winkler, B. \& Painting, R. \& Way, R. \& Jacobs, P. \& Skuce, A. 2013. Quantifying the consensus on anthropogenic global warming in the scientific literature. Environmental Research Letters 8(2), 1-7.

Corcoran, P. B., Weakland, J. P., \& Wals, A. E. (Eds.). (2017). Envisioning futures for environmental and sustainability education. Wageningen Academic.

Crane, T., \& Patterson, S. (Eds.) History of the mind-body problem. Routledge.

Crutzen, P. 2002. Geology of Mankind: The Anthropocene, Nature, 415, 23.

Crutzen, P. 2006. The "Anthropocene". In: Eckart Ehlers and Thomas Krafft (eds.) Earth System Science in the Anthropocene. Berlin Heidelberg: Springer, 13-18.

Eernstman, N. \& Wals, A. E. J. (2013). Locative Meaning-making: An arts-based approach to learning for sustainable development. Sustainability, 5. P. 1645-1660.

Foucault, M. (1995). 1975. Discipline and Punish.

Foucault, M. (2005). La hermeneutica del sujeto/The Hermeneutics of the Subject: Cursos Del College De France, 1981-1982/Lectures at the College De France, 1981-1982 (Vol. 237). Ediciones Akal.

Gay, Peter (1996), The Enlightenment: An Interpretation, W. W. Norton \& Company Giddens, A. (2009). The politics of climate change. London: Polity Press.

Glasser, H \& Hirsh, J . (2016). Towards the development of robust learning for sustainability core competencies. Sustainability 9 (3): 121-134. DOI: 10.1089/sus.2016.29054. hg

Glasser, H. (2017). Toward robust foundations for sustainable well-being societies: Learning to change by changing how we learn. In Cook, J. (Ed.) Sustainability, Human Well-being and The Future of Education. Palgrave McMillan. (Manuscript submitted for publication)

Goleman, D. (2006). Emotional intelligence. Bantam Books.

Hacking, I. (1999) The social construction of what? Harvard university press.

Hsieh, H. F., \& Shannon, S. E. (2005). Three approaches to qualitative content analysis. Qualitative health research, 15(9), 1277-1288. 
Incropera, F.P. (2015). Climate Change: A wicked problem - Complexity and uncertainly at the intersection of science, economics, politics and human behaviour. Cambridge: Cambridge University Press.

IPCC (1995) Scientific Assessments of Climate Change. The Policymaker's Summary of Working Group 1 to the Intergovernmental Panel on Climate Change, WMO/UNEP.

Kagawa, F \& Selby, D. (2010). (Eds.) Education and Climate Change: Living and Learning in Interesting Times. New York: Routledge.

Kenrick, J. (2009). Commons thinking. In The handbook of sustainable literacy: skills for a changing world, 33-8. Greenbook.

Kollmuss, A., \& Agyeman, J. (2002). Mind the gap: Why do people act environmentally and what are the barriers to pro-environmental behavior? Environmental Education Research, 8(3), 239-260.

Laininen, E. (2018). Transforming our worldview towards a sustainable future. In Cook, J. (Ed.) Sustainability, Human Well-being and The Future of Education. Palgrave McMillan. (In Press).

Lehtonen, J. \& Välimäki, J. (2012). The environmental neurosis of modern man: illusion of autonomy and the real dependence denied. In Weintrobe, S. (Ed.). Engaging with climate change. Psychoanalytic and interdisciplinary perspectives. p.48-51. Routledge.

Marcott, S. A., Shakun, J. D., Clark, P. U., \& Mix, A. C. (2013). A reconstruction of regional and global temperature for the past 11,300 years. science, 339(6124), 1198-1201.

Martusewicz, R. A. \& Edmundson, J., \& Lupinacci, J. (2014). Ecojustice education: Toward diverse, democratic, and sustainable communities Routledge.

Max-Neef, M. (2010). The World on a Collision Course and the Need for a New Economy. Ambio 39(3), 200-210.

Naess, A., \& Rothenberg, D. (1990). Ecology, community and lifestyle: outline of an ecosophy. Cambridge University Press.

Naess, A. 2008. Life's Philosophy. Reason \& Feeling in a Deeper World. The University of Georgia Press.

Nash, R. F. (1989). The Rights of Nature: A History of Environmental Ethics. Madison: University of Wisconsin Press.

Norgaard, R. B. (1994). Development betrayed. The end of progress and a coevolutionary revisioning of the future. London.

Norgaard, K. M. (2011). Living in denial: Climate change, emotions, and everyday life MIT Press.

Nussbaum, M. C. 2003. Upheavals of thought: The intelligence of emotions Cambridge University Press. 
Orr, D.(1991). What is education for?: Six myths about the foundations of modern education and six new principles to replace them. In Context: A Quarterly of Humane Sustainable Culture, 27, 59-64.

Orr, D. W. (1994). Earth in mind: On education. Environment, and the Human Prospect..

Outram, D. (2006), Panorama of the Enlightenment, Getty Publications.

Palmer, J. \& Neal, P. (2003). The handbook of environmental education. Routledge.

Phillips, M. (2009). Emotional wellbeing. The ability to research and reflect on the roots of emotional wellbeing. The handbook of sustainability literacy: Skills for a changing world. Dartington: Green Books.

Pihkala, P. (2017). "Environmental Education After Sustainability: Hope in the Midst of Tragedy." Draft of an article for "After Sustainability" Theme number of Global Discourse (2017).

Pilipenko, E. (2015). Economy as a Subsystem of the Society. Journal of Management and Strategy 6(3), 38-43.

Pittman, J. (2004), Living Sustainably through Higher Education: A Whole Systems Design Approach to Organizational Change. In Corcoran, P.B. \& Wals A.J.E (Eds), Higher Education and the Challenge of Sustainability. Problematics, Promise, and Practice, Kluwer Academic Publishers, Dordrecht (The Netherlands), pp. 199-212.

Pless, N. M., \& Maak, T. (2005). Relational Intelligence for Leading Responsibly in a Connected World. In Academy of Management Proceedings (Vol. 2005, No. 1, pp. I1-I6). Academy of Management.

Salonen, A. \& Konkka, J. (2015). An Ecosocial Approach to Well-Being: A Solution to the Wicked Problems in the Era of Anthropocene. Foro de Educación 13(19), 19-34.

Salonen, A. (2014). An Ecosocial Approach in Education. In R. Jucker ja R. Mathar (Eds..) Schooling for Sustainable Development: Concepts, Policies and Educational Experiences at the End of the UN Decade of Education for Sustainable Development. Berlin-Heidelberg: Springer, 231-233.

Sauve, L. (1999). Environmental education: Between modernity and postmodernity: Searching for an integrating educational framework. Canadian Journal of Environmental Education, 4, 936.

Sayer, A. (1989). Postfordism in question. International journal of urban and regional research $13,666-695$.

Sterling, S. (2003). Whole systems thinking as a basis for paradigm change in education: Explorations in the context of sustainability (Doctoral dissertation, University of Bath).

Sterling, S. R. (2004). Higher education, sustainability, and the role of systematic learning. In P. B. Corcoran \& A. E. J. Wals (Eds.), Higher education and the challenge of sustainability: Problems, and practice (pp. 49-70). Dordrecht, Netherlands: Higher Academic. 
Sterling, S. (2009). Ecological intelligence. The handbook of sustainability literacy, 77-83.

Sterling, S. (2010). Living in the Earth: Towards an Education for Our Time. Journal of education for sustainable development, 4(2), 213-218.

Steffen, W., Richardson, K., Rockström, J., Cornell, S. E., Fetzer, I., Bennett, E. M., ... \& Folke, C. (2015). Planetary boundaries: Guiding human development on a changing planet. Science, 347(6223), 1259855.

Stevenson, R. B. (2007). Schooling and environmental education: contradictions in purpose and practice, Environmental Education Research, 13 (2), 139-153.

Tilbury, D. (2007). Learning based change for sustainability: perspectives and pathways. Social learning, 117-131.

UNESCO. (2002). Education for Sustainability, From Rio to Johannesburg: Lessons Learnt from a Decade of Commitment, report presented at the Johannesburg World Summit for Sustainable Development, (Paris, France).

UNESCO. (2014). Shaping the Future We Want. UN Decade of Education for Sustainable Development (2005-2014) Final Report (2014), p. 198 (Paris, France).

Wacquant, L. (1996). The rise of advanced marginality: Notes on its nature and implications. Acta Sociologica 39, 121-139.

Vogel, S. (2015). Thinking like a Mall. MIT Press.

Wolff, L.-A. (2011). Nature and sustainability: An educational study with Rousseau and Foucault. Saarbrucken: Lambert academic Publishing.

Zafirovski, M. (2010), The Enlightenment and Its Effects on Modern Society, p. 144 
Table 1. Pedagogy of interconnectedness and Climate.now course materials

\begin{tabular}{|c|c|c|c|}
\hline Dichotomy & Pedagogy of interconnectedness & Learning goal (Climate.now) & Content or exercise (Climate.now) \\
\hline $\begin{array}{l}\text { Nature - Culture } \\
\text { Local - Global }\end{array}$ & $\begin{array}{l}\text { Seeing the world as relational } \\
\text { Seeing a man as a part of global eco- } \\
\text { social relations } \\
\text { Systems thinking, ecological thinking and } \\
\text { global awareness } \\
\text { Transdisciplinary learning }\end{array}$ & $\begin{array}{l}\text { Basic knowledge: climate change as a } \\
\text { scientific phenomenon, mitigating it and } \\
\text { adapting to it } \\
\text { Various perspectives of climate change: } \\
\text { Connections between the environment, the } \\
\text { economy and different parts of society } \\
\text { Recognition of climate change as a global, } \\
\text { human and ethical challenge }\end{array}$ & $\begin{array}{l}\text { Interconnected learning packages: Systems thinking, climate } \\
\text { change in different fields, big issues (international } \\
\text { negotiations, food, forestry) } \\
\text { Project assignments: Case New Orleans, Himalaya, Stepping } \\
\text { into experts'shoes in different localities }\end{array}$ \\
\hline Individual - Social & $\begin{array}{l}\text { Seeing the reality of climate change, and } \\
\text { cultural responses as socially } \\
\text { constructed and organized with each } \\
\text { person having a meaningful role in the } \\
\text { social reality } \\
\text { Collaborative learning } \\
\text { Participatory learning }\end{array}$ & $\begin{array}{l}\text { Reflection on one's personal role in climate } \\
\text { change as a person, member of society and } \\
\text { an expert of one's own field } \\
\text { Looking for solutions to climate challenge in } \\
\text { a variety of ways, and examining the } \\
\text { different perspectives, solutions, sources of } \\
\text { information and the current debate about } \\
\text { climate change from a critical point of view }\end{array}$ & $\begin{array}{l}\text { Learning diary: Reflection on personal and common images of } \\
\text { climate change, on one's personal role in climate change, } \\
\text { reflection on one's own field and future role as an expert } \\
\text { Learning diary: Carbon footprint } \\
\text { Contact session: Discourses on climate change: climate change } \\
\text { and the media } \\
\text { Learning diary: Climate change and humanity } \\
\text { Video/Learning diary: Challenges of sustainability: common } \\
\text { goods and life-affirming thinking }\end{array}$ \\
\hline $\begin{array}{l}\text { Mind - Body } \\
\text { Reason - Emotion }\end{array}$ & $\begin{array}{l}\text { Seeing the human, and learning and } \\
\text { knowing holistically } \\
\text { Embodied and experiential learning } \\
\text { Emotional awareness }\end{array}$ & $\begin{array}{l}\text { Reflection and discussion on images, } \\
\text { associations and emotional responses, and } \\
\text { ethical issues related to climate change }\end{array}$ & $\begin{array}{l}\text { Introductory exercise: Climate change around us } \\
\text { Learning diary: Reflection on ethical issues and emotional } \\
\text { responses related to climate change }\end{array}$ \\
\hline Science - Art & $\begin{array}{l}\text { Seeing creatively } \\
\text { Creative learning and visualization } \\
\text { Arts-based learning }\end{array}$ & $\begin{array}{l}\text { Creative thinking, visioning new, sustainable } \\
\text { ways of thinking }\end{array}$ & $\begin{array}{l}\text { Learning diary: Utopia assignment: world of resolved climate } \\
\text { change } \\
\text { Project assignment: Visualization solutions for climate change } \\
\text { in your own field }\end{array}$ \\
\hline
\end{tabular}

